\title{
Anti-coagulant Activity of Isolated and Partially Characterized Proteoglycans and Glycosaminoglycans from African Night Crawler [Eudrilus eugeniae Kinherg]
}

\author{
Mia Clare Marie L. Bercansil*, and Miko Lorenzo J. Belgado \\ University of the Philippines Los Baños, College, Laguna 4031
}

\begin{abstract}
Proteoglycans and glycosaminoglycans were isolated from African night crawler (Eudrilus engeniae Kinberg) and partially characterized proteoglycans (3.04 \% of lyophilized worm) were liberated from the defatted and depurinated worm samples by dissociative method using 4M urea in acetate buffer. Glycosaminoglycans (12.47\% of proteoglycan extract) were extracted using enzymatic hydrolysis of the proteoglycan extract with papain. Gel filtration chromatography using Sepharose CL-4B was used to purify and estimate the molecular weights of the proteoglycan and glycosaminoglycan fractions. Three proteoglycan fractions PGF1, PGF2 and PGF3 with estimated molecular weigths 860 $\mathrm{kDa}, 181 \mathrm{kDa}$ and $3 \mathrm{kDa}$, respectively were identified as monitored by the Bradford and modified carbazole assay. Two glycosaminoglycan fractions - GF1 (MW $=860 \mathrm{kDa})$ and GF2 (MW=140 kDa) were identified using the modified carbazole assay. Infrared spectroscopy of the GF1 and GF2 showed the possible identities of the fractions. GF1 may be a hyaluronic acid and GF2 is possibly chondroitin. Anti-coagulant assay for the extracts and fractions revealed that the glycosaminoglycan isolate has anti-coagulant activity but not the GF1 and GF2 fractions individually.
\end{abstract}

Keywords: proteoglycan; anti-coagulant; glycosaminoglycans; African night crawler

\section{INTRODUCTION}

Anticoagulants like heparin are important therapuetic agents used in treatments of thrombosis and prophylaxis (Mourao et al., 1996). These agents are tapped nowadays to reduce occurence of stroke in patients by preventing blood clot formation in blood vessels that might block these channels and lead to stroke. According to Kottkamp and colleauges in 1998 , there is a $70 \%$ stroke risk reduction of patients taking oral anticoagulants.

Glycosaminoglycans are studied from different sources because of their reported anti-coagulant activities (Mourao et al., 1996 and Ofosu et al., 1998). Proteoglycans are macromolecules composed of a core protein covalently linked to glycosaminoglycan (GAG) chain. These molecules are usually found in cellular surface and extracellular 
matrices. The carbohydrate portion of proteoglycans comprises a larger fraction in the molecule and is usually the sites of biological activity (Lehninger, 2005).

All organisms produce a variety of proteoglycans. The value of the proteoglycan is in the glycosaminoglycan component they contain. Chondroitin sulfate, heparan sulfate, hyaluronic acid and dermatan sulfate are the classes of glycosaminoglycans which have different biological activities. The usual sources of proteoglycans are organisms that are cartilaginous in nature such as animal tendons, sea sponges, sea anemones and annelids (Athukorala et al., 2006; Hamed et al., 1997, Olson et al., 2006 and Viera and Mourao, 1988).

However, invertebrates from the sea are becoming sources and are expensive so cheaper alternative sources of proteoglycans should be tapped. African night crawler (Eudrilus engeniae Kinberg) is considered as the sample since these worms can be easily cultivated and thus, it is a renewable source. It was locally used by Panay island inhabitants as a component in their traditional medicine. The concoction of the boiled worms were used to treat rheumatism and labor pains. They are also used as blood thinners. The anti-coagulant activity of the enzyme lumbrokinase which can be found in these worms were also reported (Guerrero and Guerrero, 2006).

There are no studies about the proteoglycan and glycosaminoglycan content of these worms and based on the reported effectiveness of the worm concoctions in curing ailments, biologically-active compounds might be present.

\section{EXPERIMENTAL}

All solid reagents used are analytical grade Sigma products while the solvents used are from Merck. The spectrophotometer used quantification assays was from Shimadzu. The freeze-dryer used for sample preparation was from Labconco.
Sample Preparation. Worms were washed with distilled water and were left for 24 hours without food to force the worms to release the contents of their gut. The worms were lyophilized and defatted using hexane.

Proteoglycan Extraction. Dissociative method of proteoglycan extraction from Iozo, et al., 2001 was used. $4 \mathrm{M}$ urea in cold $0.05 \mathrm{M}$ acetate buffer $\mathrm{pH} 5.8$ (with protease inhibitors) was used to homogenize the lyophilized and defatted worm samples. The mixture was left in $7{ }^{\circ} \mathrm{C}$ for $24 \mathrm{hr}$. The supernatant of the mixture was separated by centrifugation (10 $\left.000 \mathrm{rpm}, 30 \mathrm{~min}, 4{ }^{\circ} \mathrm{C}\right)$. Three volumes of cold ethanol were added to precipitate out the proteoglycans. The recovered precipitate was lyophilized and stored in the freezer.

Glycosaminoglycan Extraction. The method used was adapted from Vieira and Mourao in 1988.

Papain $(1 \mathrm{~g} / 100 \mathrm{~g}$ sample) in 0.10 acetate buffer $\mathrm{pH} 5.0$ with $5 \mathrm{mM}$ EDTA and $5 \mathrm{mM}$ cysteine was used to hydrolyze the core protein of the extracted proteoglycan to release the glycosaminoglycan component. The mixture was stirred for $24 \mathrm{hr}$ at $60{ }^{\circ} \mathrm{C}$. The mixture was cooled to room temperature and the supernatant was separated by centrifugation (10 $\left.000 \mathrm{rpm}, 30 \mathrm{~min}, 4{ }^{\circ} \mathrm{C}\right)$. Three volumes of cold ethanol was added to precipitate out the glycosaminoglycans. The precipitate was dialyzed against distilled water. The precipitate was lyophilized and stored in freezer prior to use.

Quantitative and Qualitative Tests. Total Protein Content. Total protein was determined using the Bradford assay. Bovine serum albumin was used as standard (Bradford, 1976)

Total Uronic Acid Content. One $\mathrm{mL}$ of cold tetrahydroborate solution $(190.7 \mathrm{mg}$ in $20 \mathrm{~mL}$ concentrated $\mathrm{H}_{2} \mathrm{SO}_{4}$ ) was placed in test tubes together with 100 ul of samples and galacturonic acid was used as standard. The mixture was heated for $10 \mathrm{~min}$ at $100{ }^{\circ} \mathrm{C}$. After cooling, 40 ul of $0.125 \%$ carbazole in 
ethanol was added and the solutions were incubated for $10 \mathrm{~min}$. at $100{ }^{\circ} \mathrm{C}$. The absorbance was read at $530 \mathrm{~nm}$ (Bowness, 1956).

Hexosamine Determination. Amino sugars were identified using the Elson-Morgan reaction. The samples and standards (glucosamine) were first reacted with ethyl acetoacetate in $\mathrm{NaHCO}_{3}$, heated in boiling water bath for 1 hr. After cooling to room temperature, the solutions were added with $2 \mathrm{~mL}$ Ehrlich reagent I. The magenta- colored solution that was procduced are indicative of hexosamines (Elson and Morgan, 1933).

Purification and Molecular Weight Estimation. Gel filtration chromatography with Sepharose Cl-4B was used as the packing material. $0.5 \mathrm{M}$ acetate buffer $\mathrm{pH} 5.0$ was used as the eluent. The fractions were monitored by reading the absorbance at $280 \mathrm{~nm}$ and by the modified carbazole assay for hexauronic acid. Molecular weight standards were used for the estimation of the molecular weight of the fractions.

Infrared Spectroscopy. The IR spectrum were generated using the Shimadzu IR Prestige-21 Fourier Transform Infrared Spectrometer equipped with Diffuse Reflectance Accessory. The samples were ground with $\mathrm{KBr}$.

Anticoagulant Assay. Anticoagulation activity was tested by comparing the clotting times of the extracts with heparin. Sodium citrate $(3.8 \%)$ was used as the anticoagulant during blood extraction. Blood plasma was separated from other components using a centrifuge $(2400 \mathrm{Xg}, 20 \mathrm{mins})$. The coagulation was triggered by addition of $0.2 \mathrm{~mL} 1 \% \mathrm{CaCl}_{2}$ to $0.5 \mathrm{~mL}$ citrated plasma. The absorbance of the solution was read at $470 \mathrm{~nm}$ for every $10 \mathrm{~s}$ until the absorbance reaches 0.8 (coagulation) (Swoap and Kuzienga, 1949).

Statistical Analysis. SAS 9.1.3 was used as the computer software for all the statistical analysis.

\section{RESULTS}

Proteoglycan Isolation. The proteoglycans extracted from the African night crawler (Eudrilus engeniae) were around 3.04\% of the weight of the lyophilized sample. The isolate was tested for the presence of uronic acids via the modified carbazole assay. Red-colored complex was formed which was indicative of the presence of hexauronic acid residues. The isolates gave positive results to Bradford assay indicating presence of the protein portion of the proteoglycan.

Glycosaminoglycan Extraction from the Proteoglycan Isolate. Hydrolysis via the use of papain liberated the glycosaminoglycans from the core protein of the proteoglycans $(12.47 \%$ of the isolated proteoglycan by weight). The dialyzed precipitated hydrolysis products provided positive results to modified carbazole assay.

Fractionation and Estimation of Molecular Weights of Proteoglycans and Glycosaminoglycans. Both the proteoglycan isolate and the glycosaminoglycan extract were subjected to gel filtration chromatography using Sepharose CL-4B. Three proteoglycan fractions were identified using the modified carbazole assay as detection method. PGF1, PGF2 and PGF3 had the estimated molecular weights of $860 \mathrm{kDa}, 181 \mathrm{kDa}$ and $3 \mathrm{kDa}$, respectively. PGF1 contains the highest amount of hexauronic acid $(0.508 \mathrm{ug} / \mathrm{mL})$ while PGF3 had the lowest $(0.004 \mathrm{ug} / \mathrm{mL})$. PGF2, on the other hand contains the highest amount of protein $(0.023 \mathrm{ug} / \mathrm{mL})$ and PGF3 had the lowest amount $(0.017 \mathrm{ug} / \mathrm{mL})$.

The glycosaminoglycans from papain hydrolysis were also fractionated using the

Table 1. Protein and Hexauronic Acid Content of the Proteoglycan Samples.

\begin{tabular}{ccc}
\hline Fraction & $\begin{array}{c}\text { Protein, } \\
\text { ug/mL }\end{array}$ & $\begin{array}{c}\text { Hexauronic } \\
\text { acid, ug } / \mathrm{mL}\end{array}$ \\
\hline PGF1 & 0.021 & 0.508 \\
\hline PGF2 & 0.023 & 0.013 \\
\hline PGF3 & 0.017 & 0.004 \\
\hline
\end{tabular}


same column. Two fractions were obtained. GF1 has a molecular weight of $860 \mathrm{kDa}$ while GF2 has a molecular weight of $140 \mathrm{kDa}$.

Qualitative Tests. Colorimetric tests for hexauronic acids and hexosamine presence gave positive results for the fractions isolated.

\section{Infrared Spectroscopy of the} Glycosaminoglycan Fractions. Both GF1 and GF2 were subjected to IR spectroscopy. The prominent peaks from the IR spectra of these two fractions were compared to the IR spectrum of standard chondroitin sulfate and hyaluronic acid (Bansil et.al, 1978). Table 2 shows the prominent peaks from the IR spectrum (Figure 1).

Anticoagulant Activity. The proteoglycan (PG), fractions (PGF1 and PGF2), glycosaminoglycan (GAG) and glycosaminoglycan fractions (GF1 and GF2) were subjected to anti-coagulant activity assessment. Plasma from freshly-drawn human blood was used.The positive control used for this assay was heparin and $\mathrm{CaCl}_{2}$ was used as the clotting factor. The test was done in three replicates. Table 3 shows the

Table 2. Prominent IR peaks for GF1 and GF2.

\begin{tabular}{ccc}
\hline $\begin{array}{c}\text { GF1 } \\
\text { Peaks, } \\
\mathbf{c m}^{-1}\end{array}$ & $\begin{array}{c}\text { GF2 } \\
\text { Peaks } \\
\text { cm }^{-1}\end{array}$ & Peak Assignments \\
\hline 1043.49, & 1043.49, & C-O-C \\
1014.56 & 1014.56 & $-\mathrm{OH}(\mathrm{ROH})$ \\
\hline 3550 & 3429.43 & $-\mathrm{OH}(\mathrm{RCOOH})$ \\
\hline 3263.56 & 3277.06 & C-O-H $(\mathrm{RCOOH})$ \\
\hline 921.97 & 921.97 & $\mathrm{C}-\mathrm{O}-\mathrm{H}(\mathrm{ROH})$ \\
\hline 1338.80 & 1340.53 & $\mathrm{~N}-\mathrm{H}$ stretch \\
\hline 3263.56 & 3277.06 & $\mathrm{C}=\mathrm{O}$ bending \\
& & $\begin{array}{c}\text { NH } \\
\text { (amide } \text { ) }\end{array}$ \\
\hline 1695.43 & 1695.43 & $\begin{array}{c}\text { Couple NH } \\
\text { deformation; } \\
\text { CN stretch } \\
\text { (amide II) }\end{array}$ \\
\hline 1560.41 & 1560.41 & N-H wag \\
\hline 648.08 & 646.16 &
\end{tabular}
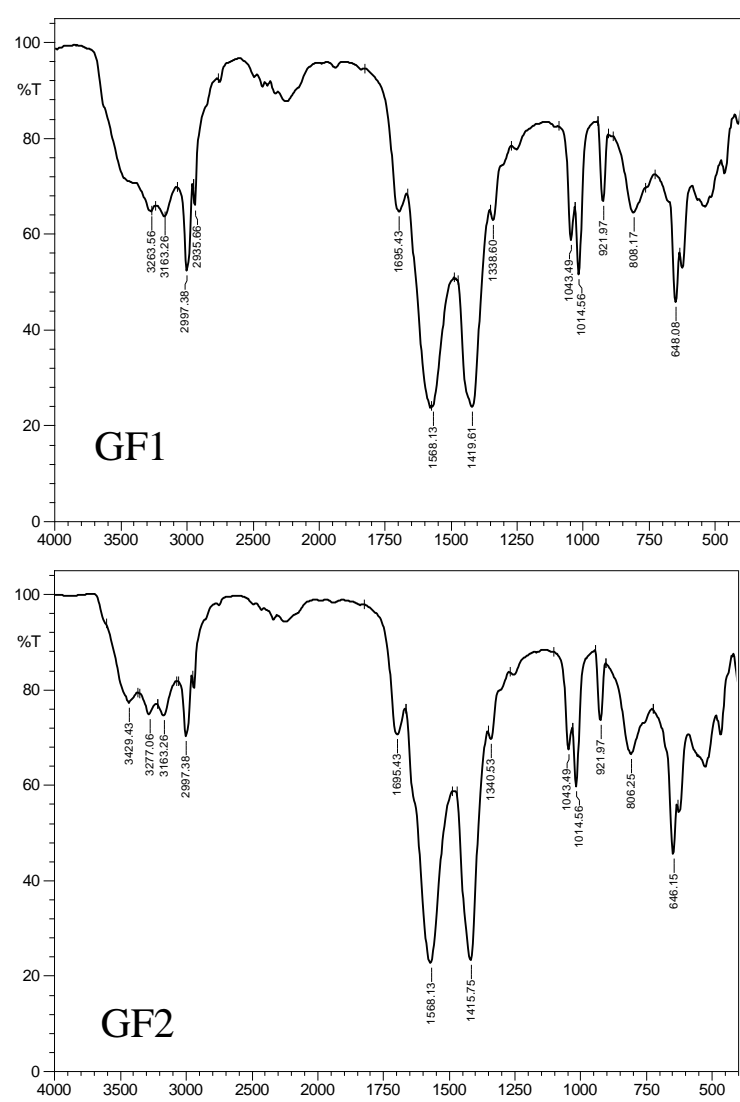

Figure 1. IR Spectrum.

estimated clotting times based on the change in absorption of the test solutions at $470 \mathrm{~nm}$.

At $95 \%$ confidence interval, the GAG isolate is significantly different from all the other treatments. The GAG is a potent anticoagulant but not as potent as heparin.

The GAG isolate passed the heparin anticoagulant test (minimum of $20 \mathrm{~min}$ before coagulation is observed). This is according to the method of Swoap and Kuzienga, 1949.

\section{DISCUSSION}

Isolation, Fractionation and Molecular Weight Determination of Proteoglycans and Glycosaminoglycans from African nightcrawler. Proteoglycans $\quad(3.04 \%$ of lyophilized sample) and glycosaminoglycan fractions $(12.47 \%$ of preoteoglycan isolate) were isolated from African night crawler.

The isolates were tested for the presence of uronic acid via the modified carbazole assay to identify if proteoglycans are present since 
Table 3. Clotting Time of Blood Plasma with Different Test Solutions.

\begin{tabular}{cc}
\hline Treatment & Clotting Time, min \\
\hline Heparin (positive) & No clotting \\
\hline Plasma (negative) & $4: 30$ \\
\hline PG & $15: 20$ \\
\hline PGF1 & $11: 00$ \\
\hline PGF2 & $16: 00$ \\
\hline PGF3 & $13: 20$ \\
\hline GAG & $53: 30$ \\
\hline GF1 & $12: 30$ \\
\hline GF2 & $15: 30$
\end{tabular}

hexauronic acids are sugar moieties that can be found in the repeating disaccharide units of glycosaminoglycans. All of the glycosaminoglycans (hyaluronates, chondroitin sulfates, dermatan sulfates and heparan sulfates) have uronic acid residues except for keratan sulfate (Hardingham and Fosang, 1992). Red or magenta-colored solutions for the proteoglycans are indicative of the presence of hexauronic acids from the modified carbazole assay. Since the fractions gave positive results to this test, the probability of having keratan sulfate in the fractions is eliminated.

The Bradford assay was done to determine the presence of the protein portion of the proteoglycan. Formation of blue-colored solutions from the proteoglycan isolate are indicative of the presence of protein.

Papain hydrolysis of proteoglycans liberated the glycosaminoglycan components. The ethanol precipitated glycosaminoglyacans were dialyzed against distilled water for 24 hours to remove the other contaminants (e.g. papain, core protein and salt). The MWCO of the dialyzing bag used was 10000 Da. Any molecule with a molecular weight lower than the MWCO will diffuse outside of the bag. The precipitate was also tested for the presence of glucuronic acid using the modified carbazole assay giving positive results.

Qualitative test for hexosamines was also conducted to determine the presence of amino sugars. Aside from uronic acids, the the usual other component of the disaccharide moiety of glycosaminoglycans are amino sugars or $\mathrm{N}$-acetylated sugars.

The proteoglycans and glycosaminoglycan isolates were fractionated using gel filtration chromatography providing three proteoglycan fractions and two glycosaminoglycan fractions. The molecular weights of these fractions were also estimated. The molecular weights for PGF1, PGF2 and PGF3 were about $860 \mathrm{kDa}, 181 \mathrm{kDa}$ and $3 \mathrm{kDa}$, respectively while for the glycosaminoglycan fractions, GF1 has an estimated molecular weight of $860 \mathrm{kDa}$ and GF2 has $140 \mathrm{kDa}$.

From this, PGF1 and GF1 had the same estimated molecular weights. The GF1 fraction might be hyaluronic acid, the only proteoglycan that does not contain a protein core. The action of papain did not reduce the molecular weight of GF1 showing the presence of a glycosaminoglycan without a protein core.

The molecular weight of GF1 is also in the range (100 to $1000 \mathrm{kDa}$ ) of naturally occurring hyaluronic acids as reported by Hardingham and Fosang in 1992. On the other hand, GF2 cannot be keratan sulfate because of the presence of hexauronic acids which are not found on this type of glycosaminoglycan. The GF2 fraction maybe the glycosaminoglycan portion of PGF2. Deducting the molecular weight of GF2 $(140 \mathrm{kDa})$ from the molecular weight of PGF2 (181 kDa), the estimated molecular weight of this core protein of PGF2 is $41 \mathrm{kDa}$. There are reported leucine-rich proteoglycans having core protein sizes of about $40 \mathrm{kDa}$ and usually contains two chains of chondroitin or keratan sulfate (Hardingham and Fosang, 1992).

On the other hand, the GF2 fraction is relatively large but there are reports of chondroitin and keratan sulfates from lumpsucker fish having molecular weights of $120 \mathrm{kDa}$ (Panagos et al., 2014).

Based on the estimated molecular weight, the GF2 fraction cannot be heparan sulfate or dermatan sulfate since the molecular weight 
ranges of these glycosaminoglycans are $5 \mathrm{kDa}$ to $50 \mathrm{kDa}$ and $10 \mathrm{kDa}$ to $100 \mathrm{kDa}$, respectively which is according to Fraser and collegues in 1997.

The PGF3 fraction might not be a proteoglycan due to the very low amount of hexauronic acid it contains and very low molecular weight. This might also be removed in the dialysis portion in purifying the glycosaminoglycans since PGF3's molecular weight is below that of the MWCO of the dialyzing bag. Also, the dissociative process of proteoglycan isolation usually extracts chondroitin sulfates of high molecular weights while the associative method (lower urea concentration) extracts the other proteoglycans (Iozzo et al., 2001).

\section{Characterization of Glycosaminoglycans} using Infrared Spectroscopy. Infrared spectroscopy was used to further characterize the two glycosaminoglycans. Based on the molecular weights and quantitative tests, the identity of these two fractions can be hyaluronic acid and chondroitin sulfate. The prominent peaks listed on Table 2 were corelated to the peaks from the chondroitin sulfate standard and the spectra of hyaluronic acid from Bansil et al. in 1982. Figure 2 shows the structure of the repeating disaccharide unit of hyaluronic acid (glucuronic acid bound by $\beta-1,3$ linkage to $\mathrm{N}$ acetyl glucosamine) and chondroitin sulfate (glucuronic acid bound by $\beta-1,3$ linkage to $\mathrm{N}$ acetylgalactosamine sulfated at carbon 6 ).
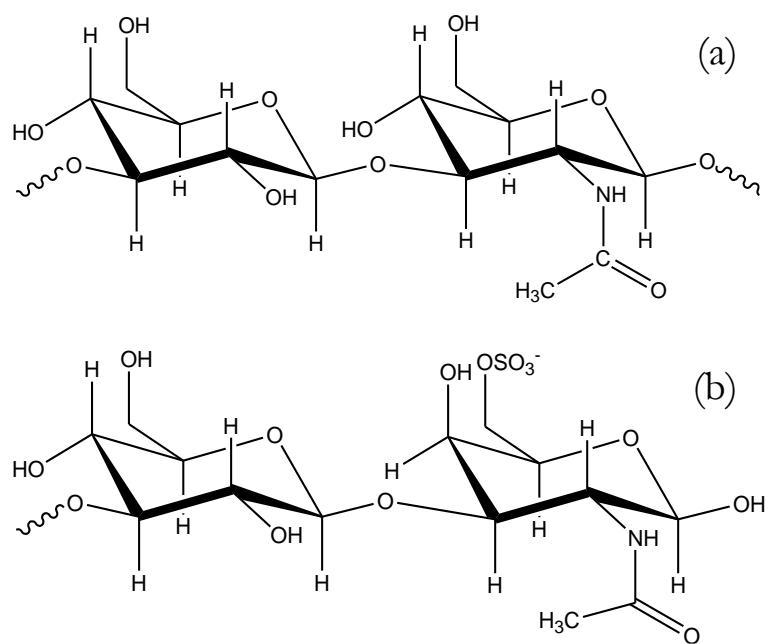

Figure 2. Structures of disaccharide moieties of (a) byaluronic acid and (b) chondroitin sulfate.
The strong absorbance at around 1695 can be due to the $\mathrm{C}=\mathrm{O}$ of the carboxylic acid portion of glucuronic acid residue on the disaccharide component of the samples. The peak for the ether functional group (glycosidic linkages between monosaccharides) is estimated to be at around $1043 \mathrm{~cm}^{-1}$.

Due to the limited amount of hyaluronic acid standard, there was no IR spectrum generated. Haxaire et al. in 2002 studied the IR spectrum of hyaluronic acid. Included in the prominent bands in the IR spectrum of dried HA were the following: bands at 950 and $1200 \mathrm{~cm}^{-1}$ are attributed to the vibrations of the $\mathrm{C}-\mathrm{O}$ in the alcohol functionality. These values are close to the $921.97 \mathrm{~cm}^{-1}$ peak and $1338.80 \mathrm{~cm}^{-1}$. The symmetric vibrations of the $\mathrm{COO}^{-}$group is assigned to band at $1400 \mathrm{~cm}^{-1} ; 1500$ to 1700 $\mathrm{cm}^{-1}$ for the amide I and amide II and other $\mathrm{C}=\mathrm{O}$ groups; and bands at 2500 to $3600 \mathrm{~cm}^{-1}$ for the $\mathrm{N}-\mathrm{H}$ and $\mathrm{O}-\mathrm{H}$ stretches.

The presence of sulfated Nacetylgalactosamine in the disaccharide moiety of chondroitin sulfate spells the difference between it and hyaluronic acid. The IR spectrum of chondroitin sulfate showed a peak at $1236 \mathrm{~cm}^{-1}$ which is near the value for the characteristic valence vibration of sulfate residue or S-O stretch $\left(1240 \mathrm{~cm}^{-1}\right)$ according to Servaty et al. in 1998. Fraction GF2 has no peak at $1240 \mathrm{~cm}^{-1}$ as compared to the band from the spectrum of chondroitin sulfate. This might be attributed to a low-sulfated or non-sulfated chondroitin sulfate structure. There are reports regarding the occurrence of these types of chondroitin sulfate or chondroitins.

Caenorhabditis elegans (nematode) was reported to have novel non-sulfated chondroitin proteoglycans. There is the absence of the sulfate group on $\mathrm{N}$-acetylgalactosamine. According to Olson et al. in 2006, there are little reports about the proteoglycans of invertebrates including $C$. elegans. The metabolic pathways for proteoglycans is conserved completely in C.elegans, mice and human. However, the epimerases and sulfotransferases present in vertebrates are 
lacking in C. elegans so the GalNAc residues are left unmodified (Olson et al. 2006).

Karamanos et al. in 1990 showed the occurrence of non-sulfated chondroitin proteoglycans from squid skin which is also attributed to the absence of specific sulfotransferases in the Golgi apparatus where the modification of the sugars in these biomolecules occur.

As shown in Figure 1, GF1 and GF2 had similar prominent peaks because the structure of the non-sulfated chondroitins will just be the same as the structure of hyaluronic acids but they will differ only in the molecular weight range.

Based on Fraser and colleagues in 1997, the average molecular weight of hyaluronic acids can reach up to $1 \times 10^{5}$ to $1 \times 10^{7} \mathrm{Da}$ while chondroitin sulfates can have MW from 10 $000 \mathrm{Da}$ to $70000 \mathrm{Da}$. GF1 fraction is in the molecular weight range for hyaluronic acids while GF2 is high above the average range for chondroitins.

\section{Anti-coagulant Activity of Proteoglycans and Glycosaminoglycans from African nightcrawler. Figure 3 shows the change in the absorbance of the test solutions at $470 \mathrm{~nm}$ for 10 second intervals. It can be seen that the sharp change in the slope is the start of coagulation. It can be noted that there is no significant increase in the slope of the heparin-treated plasma showing no signs of coagulation.}

The anticoagulant activity of heparin and other related glycosaminoglycans can be attributed the inhibition of the intrinsic pathway for the prothrombin activation. Calcium ions activate the pathway to produce thrombin that will lead to fibrin clot formation. Heparin can bind to antithrombin III which leads to a cascade of reactions resulting in the thrombin-antithrombin III complex formation that leads to anticoagulation. Since hyaluronic acids and chondroitins have similar structures with heparin, they might follow the same mechanism (Ofosu, 1988).

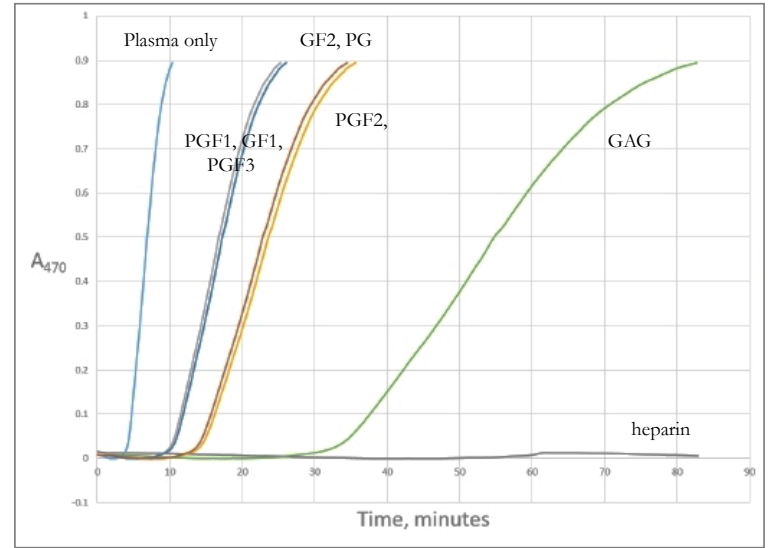

Figure 3. Absorbance at $470 \mathrm{~nm}$ of test solutions for anticoagulant assay.

Anti-coagulation of blood is important to prevent high-blood pressures and stroke accompanying it.

\section{SUMMARY AND CONCLUSION}

Three proteoglycan fractions were identified PG1, PG2 and PG3 from the African night crawler. The first two fractions have molecular weights in the range of known proteoglycans $(860 \mathrm{kDa}$ and $181 \mathrm{kDa}$, repectively) but PG3 ha a very low molecular weight.

Two glycosaminoglycan fractions were isolated. GF1 and GF2 have molecular weights (860 kDa and $140 \mathrm{kDa}$, respectively) which are also within the range of reported glycosaminoglycans. GF1 maybe hyaluronic acid due to its high molecular weight and similar IR peaks with standard hyaluronic acid. GF2 on the other hand, may be a non-sulfated chondoitin sulfate due to the absence of IR peak of GF2 corresponding to the sulfate stretch. The mixture of GF1 and GF2, not individual fractions proved to have blood anticoagulant properties but not as potent as heparin.

\section{RECOMMENDATIONS}

Disaccharide composition analysis should be done to further characterize the fractions. PGF3 should be further analyzed as it might be a low molecular weight proteoglycan. Other biological activity assays should also be conducted. 


\section{ACKNOWLEDGEMENT}

This study will not be possible without the financial support from DA-BIOTECH PIU and equipment used from the Insitute of Chemistry UPLB. Gratitude should also be given to Dr. Leticia Olivera of CINVESTAB Mexico for providing us with the hyaluronic acid standard.

\section{REFERENCES}

Athukorala Y, Lee KW, Kim SK, Jeon YJ. Anticoagulant activity of marine green and brown algae collected from Jeju Island in Korea. Bioresource Technol. 2006; 690-756.

Bansil R, Yannas LV, Stanley HE. Raman spectroscopy: A structural probe of glycosaminoglycans. Biochim Biophys Acta. 1978; 541:535-542.

Bradford MM. A dye binding assay for protein. Anal Biochem. 1976; 72:248-254.

Bowness JM. Application of the carbazole reaction to the estimation of glucuronic acid and glucose in some acidic polysaccharides and in urine. Biochem J. 1956; 67:295-300.

Bowness JM. 5-Formylfuroic acid and the carbazole reaction for uronic acids and acidic polysaccharides. Biochem J. 1957; 70:107-110.

Elson LA, Morgan WTJ. A colorimetric method for the determination of glucosamine and chondrosamine. Biochemistry. 1933; 27:1824-1828.

Fraser JRE, Laurent TC, Laurent BG. Hyaluronan: Its nature, distribution, functions and turnover. J Intern Med. 1997; 242:27-33.

Guerrero R. Earthworm culture for vermicompost and vermimeal production and for vermiceutical application in the Philippines (1978-2008) - A Review. Dynamic Soil, Dynamic Plant. Global Science Books; 2009.
Hamed RR, Maharem TM, El-Guindy AS. Proteoglycans from adult worms of Schistosoma haematobium. J Helminthol. 1997; 71:151-160.

Hardingham TE, Fosang AJ. Proteoglycans: many forms and many functions. FASEB J. 1992; 6: 861-870.

Iozzo RV, Ed. Methods of Molecular Biology: Proteoglycan Protocols. Elsevier Scince; 2001.

Karamanos NK, Aletras AJ, Antonopoulos CA, Hjerpe A, Tsiganos CP. Chondroitin proteoglycans from squid skin. Isolation, characterization and immunological studies. Eur J Biochem. 1992; 192:33-38.

Kottamp H, Hindricks G, Breithardt G. 1998. Role of anti-coagulant therapy in atrial fribillation. J Cardiovasc Electro. 1998; 9:8696.

Nelson DL, Cox MM. Lehninger Principles of Biochemistry. W. H. Freeman; 2005.

Ofosu FA. Mechanisms for the anticoagulant effect of heparin and related polysaccharides. Nouv Rev Fr Matol. 1988; 30(3): 155-160.

Olson SK, Bishop JR, Yates JR, Oegema K, Esko JD. Identification of novelchondroitin proteoglycans in Caenorbobditis elegans: embryonic cell division depends on CPG-1 and CPG-2. J Cell Biol.2006; 173(6):985-994.

Panagos CG, Moss TD, Bavington CD, Olafsson HG, Uhrín D. Characterization of hyaluronic acid and chondrotin/dermatan sulfate from lumpsucker fish C. lumpus. Carbohyd Polym. 2014; 106:25-33.

Swoap OF, Kuzienga MH. 1949. The sheep plasma method for the bioassay of heparin preparations. J Am Pharm Assoc. 1949; 38:563-565. 